\title{
Retrospective Study of Spectrum of Ovarian Tumours in a Tertiary Care Setup
}

\author{
Vimala Chelladurai*, Vimal Chander and Chitra Srinivasan \\ Department of Pathology, Saveetha Medical College and hospital, Saveetha University, Thandalam, Chennai (India)
}

\begin{abstract}
Background: Ovarian cancer accounts for $3 \%$ of all cancers in women. $80 \%$ of the ovarian tumors are benign, occurring in the age group of 20 to 45 years whereas malignant tumors are common in elderly women, between 45 to 65 years. Ovarian cancer is the sixth most common cancer (age standardized incidence rate of $6.6 / 100,000$ ) and the seventh leading cause of cancer deaths (age standardized mortality rate of 4/100,000) among women worldwide

Methods: All ovarian tumors diagnosed over a period of 39 months from January 2014 to March 2017 in the Department of Pathology, Saveetha Medical College, Thandalam, Chennai, Tamil Nadu were included in this study

Result: Out of a total of 61 ovarian tumor specimens, 53 were surface epithelial tumors and 4 were germ cell tumors and 4 were sex cord stromal tumors. Out of 61 cases, there were 52 benign, 8 malignant and 1 borderline tumors. Most common histological type was surface epithelial tumors. Most common benign tumor was serous cystadenoma (42 cases) and the malignant tumor was serous cystadenocarcinoma (4 cases).

Conclusion: The most common ovarian tumor was surface epithelial tumors and the most common benign tumor among surface epithelial tumor was serous cystadenoma. The commonest malignant tumor was surface epithelial tumor which was common among patients who are above 60 years of age.
\end{abstract}

Keywords: Ovarian Cancer, Surface Epithelial Tumours, Serous Cystadenoma, Germ Cell Tumours, Sex Cord Stromal Tumours

\section{Introduction}

Ovarian cancer accounts for $3 \%$ of all cancers in women. $80 \%$ of the ovarian tumors are benign, occurring in the age group of 20 to 45yearswhereas malignant tumors are common in elderly women, between 45 to 65 years. ${ }^{[1]}$ Ovarian cancer is the sixth most common cancer (age standardized incidence rate of $6.6 / 100,000)$ and the seventh leading cause of cancer deaths (age standardized mortality rate of 4/100,000) among women worldwide. ${ }^{[2]}$

In most of the population-based cancer registries in India, ovarian cancer is the third leading site of cancer among women, leaving behind cervix and breast. The age adjusted incidence rates of ovarian cancer vary between 5.4 and 8.0 per 100,000 population in different parts of the country ${ }^{[3]}$. Ovarian cancer has the worst prognosis among all gynecological malignancies. The overall 5-year survival rate is approximately $45 \%$, mainly due to diagnosis at a later stage $\cdot{ }^{[4]}$

During the period from 2001 to 2006, the age standardized incidence rate (ASR) for ovarian cancers varied from 0.9 to 8.4 per 100,000 person-years among various registries. The age specific incidence rate (ASIR) for ovarian cancer started from 35years of age and reached a peak from 55 and 64years age ${ }^{[5]}$ This study aims to find out the incidence of tumors of ovary in a tertiary care center.

\section{Materials and Methods}

It is a hospital based retrospective study conducted in the Department of Pathology, Saveetha Medical College, Thandalam, Chennai, Tamil Nadu, after getting the approval from the institutional ethical committee. All ovarian tumors diagnosed over a period of 39 months from January2014 to March 2017 were included in this study. The macroscopic and the microscopic features of the cases were studied and analyzed.

Inclusion Criteria: All cases diagnosed to have ovarian neoplasm over a period of 39 months from January 2014 to March 2017

Exclusion Criteria: Non-ovarian and Non-neoplastic ovarian lesions were excluded from this study.

\section{Results}

Out of a total of 61 ovarian tumor specimens,53 were surface epithelial tumors and 4 were germ cell tumors and 4 were sex cord stromal tumors. Out of 61 cases, there 
were 53 benign, 7 malignant and 1 borderline tumors. (Table 1) Most common histological type was surface epithelial tumors. Most common benign tumor was serous cystadenoma(42 cases) and the malignant tumor was serous cystadenocarcinoma(4 cases).

Predominantly the tumors were unilateral (Table 2). The size of the tumors ranged from $1.5 \mathrm{~cm}$ to $30 \mathrm{~cm}$.Right side was commonly affected (31 cases) among unilateral tumors. Additional finding of adenomyosis was found in 2 cases of serous cystadenoma and 1 case of serous cystadenocarcinoma ovary.Out of 53 surface epithelial tumors, 11 were multiloculated cysts, out of which 6 were benign, 4 malignant and 1 borderline.

Age range varied from 15 to 75 years with a mean of44 years for all ovarian lesions. Most ovarian lesions (16 cases) were seen between 41 to 50 years of age (Table 3 ). Serous cystadenoma was common in 21 to 50years and more than 60years of age. Most common malignant tumor (serous cystadenocarcinoma) was common in more than 60 years age group.

For all age groups, benign neoplasms were more common than malignant neoplasms. 53cases of benign neoplasms were observed in all age groups out of 61 cases, which comprised $86.8 \%$ among ovarian neoplasms. Malignant tumours were $7(11.4 \%)$ and Borderline tumour was 1 $(1.6 \%)$ in number. (Figure 1)

Clinical Presentation of: There were 5 patients without symptoms which were detected on routine pelvic examination during ultrasonogram or cesarean section or abdominal hysterectomy. Most of the patients presented with lower abdominal pain (18 cases), 3 patients presented with abdominal mass or distension. Constitutional symptoms such as loss of appetite and weight loss in 2 patients were present in malignant cases only. Many patients had more than one symptoms such as menstrual abnormalities, abnormal vaginal bleeding, urinary symptoms and GIT symptoms(Figure 4).

Size: Grossly, the ovarian lesions were of variable size ranging from $1.5 \mathrm{~cm}$ to $30 \mathrm{~cm}$. The majority of the ovarian lesions in this study ranged from $10 \mathrm{~cm}$ to $25 \mathrm{~cm}$ in maximum dimension.

Consistency: The consistency of ovarian lesions varied from cystic, partially solid and partially cystic to solid. Out of 61 ovarian lesions, $73 \%$ (45 cases) were cystic.

Laterality: Among 61cases, 33 were found in the right ovary and 23 in the left ovary. 5 cases had bilateral ovarian lesions, out of which 1case was malignant.

Table 1: Histological types of ovarian lesions.

\begin{tabular}{|c|c|c|c|c|}
\hline Histologic type & Benign & Borderline & Malignant & Total \\
\hline Serous & 34 & 0 & 3 & 37 \\
\hline Serous cystadenofibroma & 5 & 0 & 0 & 5 \\
\hline Fibrothecoma & 2 & 0 & 0 & 2 \\
\hline Borderline mucinous & 0 & 1 & 0 & 1 \\
\hline Mucinous & 7 & 0 & 1 & 8 \\
\hline Endometrioid & 0 & 0 & 1 & 1 \\
\hline Brenner & 1 & 0 & 0 & 1 \\
\hline Granulosa cell tumor & 0 & 0 & 1 & 1 \\
\hline Mature teratoma & 4 & 0 & 0 & 2 \\
\hline Immature teratoma & 0 & 0 & 1 & 1 \\
\hline
\end{tabular}

Table 2: Laterality of ovarian tumors

\begin{tabular}{|l|c|c|c|}
\hline Diagnosis & Unilateral & Bilateral & Total \\
\hline Serous cystadenoma & 26 & - & 26 \\
\hline Mucinous cystadenoma & 4 & - & 4 \\
\hline Endometrioid & 1 & 1 & 2 \\
\hline Serous cystadenofibroma & 1 & 2 & 3 \\
\hline Serous cystadenocarcinoma & 1 & - & 1 \\
\hline Mucinous cystadenocarcinoma & 1 & - & 1 \\
\hline Brenner's tumor & 1 & - & \\
\hline Granulosa cell tumor & 1 & - & \\
\hline Mature cystic teratoma & 2 & 3 & \\
\hline Total & 38 & & 2 \\
\hline
\end{tabular}


Table 3: Age distribution of various histological types of ovarian lesions

\begin{tabular}{|c|c|c|c|c|c|c|c|c|}
\hline \multirow{2}{*}{$\begin{array}{l}\text { Age (in } \\
\text { years) }\end{array}$} & \multicolumn{3}{|c|}{ Surface epithelial tumors } & \multirow{2}{*}{$\begin{array}{c}\text { Sex cord } \\
\text { stromal } \\
\text { tumors }\end{array}$} & \multicolumn{2}{|c|}{ Germ cell tumors } & \multirow[t]{2}{*}{ Total } & \multirow[t]{2}{*}{ Percentage } \\
\hline & Benign & Borderline & Malignant & & Benign & Malignant & & \\
\hline$<20$ & 4 & 0 & 0 & 0 & 0 & 0 & 4 & $6.5 \%$ \\
\hline $21-30$ & 8 & 0 & 1 & 0 & 1 & 1 & 11 & $18 \%$ \\
\hline $31-40$ & 8 & 0 & 1 & 0 & 2 & 0 & 11 & $18 \%$ \\
\hline $41-50$ & 13 & 1 & 0 & 2 & 0 & 0 & 16 & $26.2 \%$ \\
\hline $51-60$ & 5 & 0 & 0 & 1 & 1 & 0 & 7 & $11.4 \%$ \\
\hline$>60$ & 8 & 0 & 4 & 0 & 0 & 0 & 12 & $19.6 \%$ \\
\hline Total & & 53 & & 3 & 4 & 1 & 61 & $100 \%$ \\
\hline
\end{tabular}

Table 4: Shows the microscopic features of Surface epithelial tumour

\begin{tabular}{|c|c|}
\hline Microscopy & Number of cases \\
\hline Necrosis(Gross /Microscopy) & 4 \\
\hline Serous tumour with focal mucin production & 2 \\
\hline Psammoma bodies & 1 \\
\hline Lymphovascular emboli & 3 \\
\hline Hemorrhage (Gross/Microscopy) & 2 \\
\hline Tortion & 2 \\
\hline
\end{tabular}

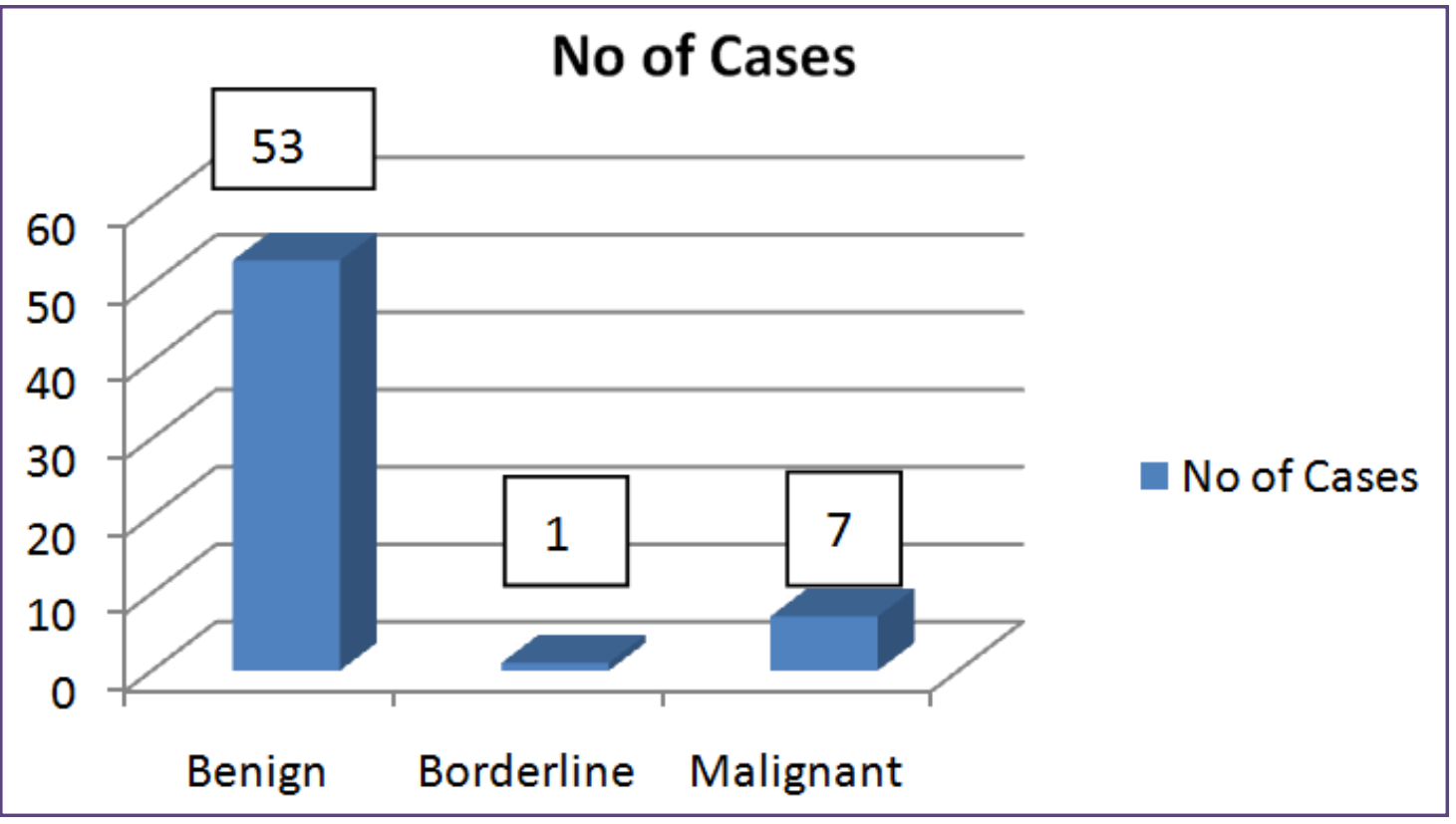

Fig. 1: Number of neoplasms for all age group 


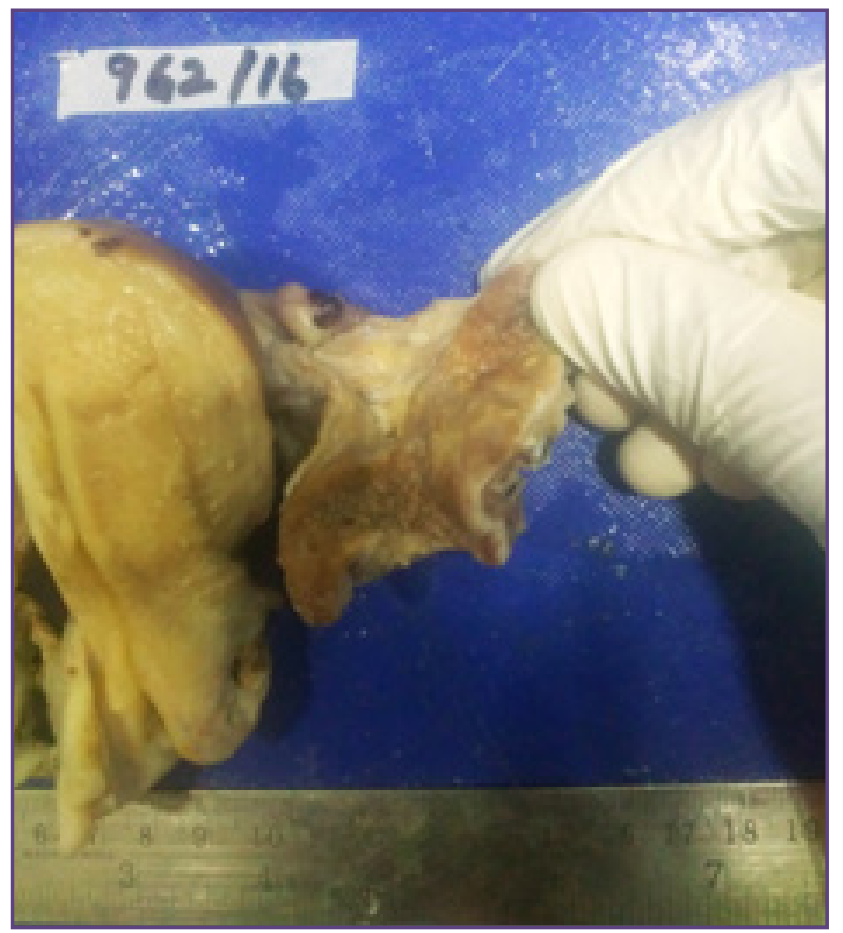

Fig. 2: Serous cystadenocarcinoma ovary

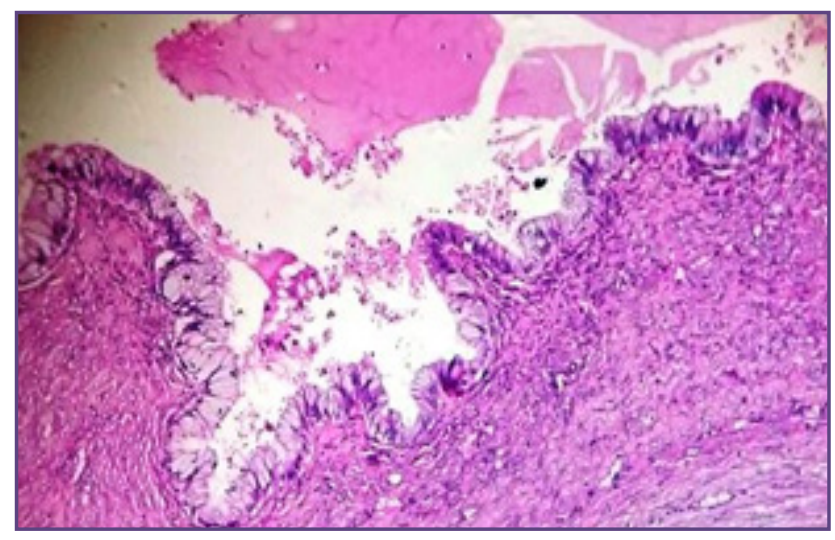

Fig. 3: Mucinous cystadenocarcinoma 10x

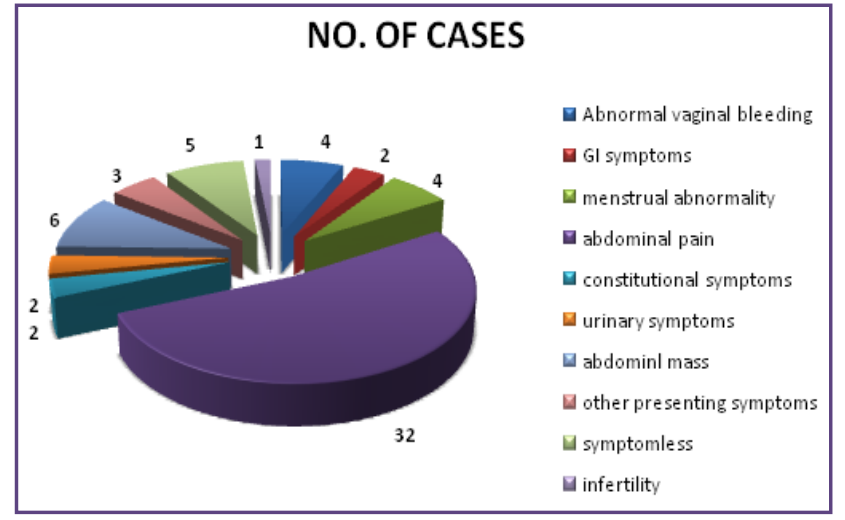

Fig. 4: Clinical presentation of cases of ovarian tumors

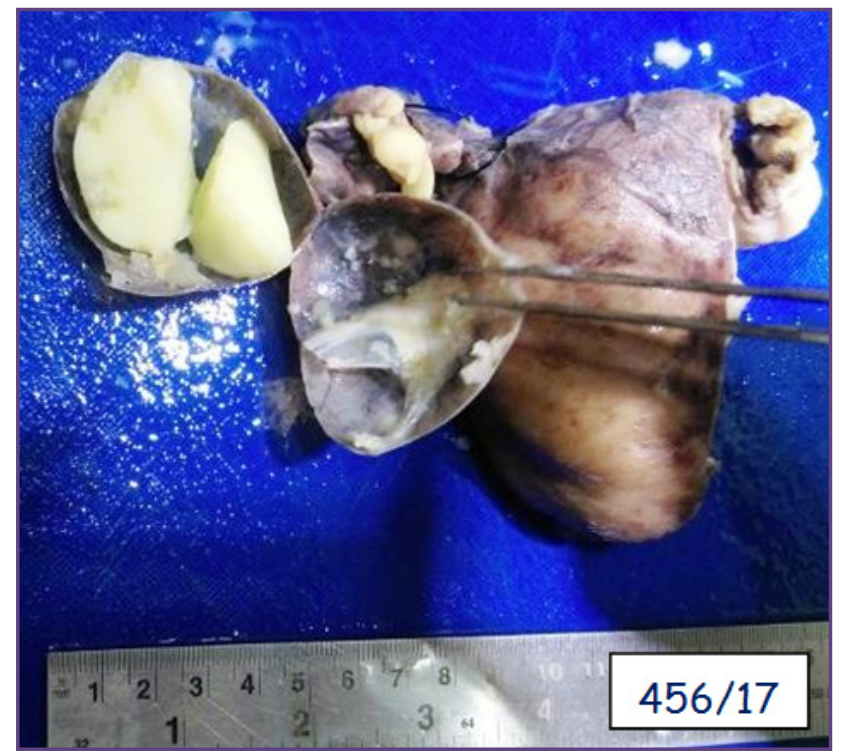

Fig. 5: Borderlinemucimnoustumour - Left ovary appearing cystic with papillay excrescences

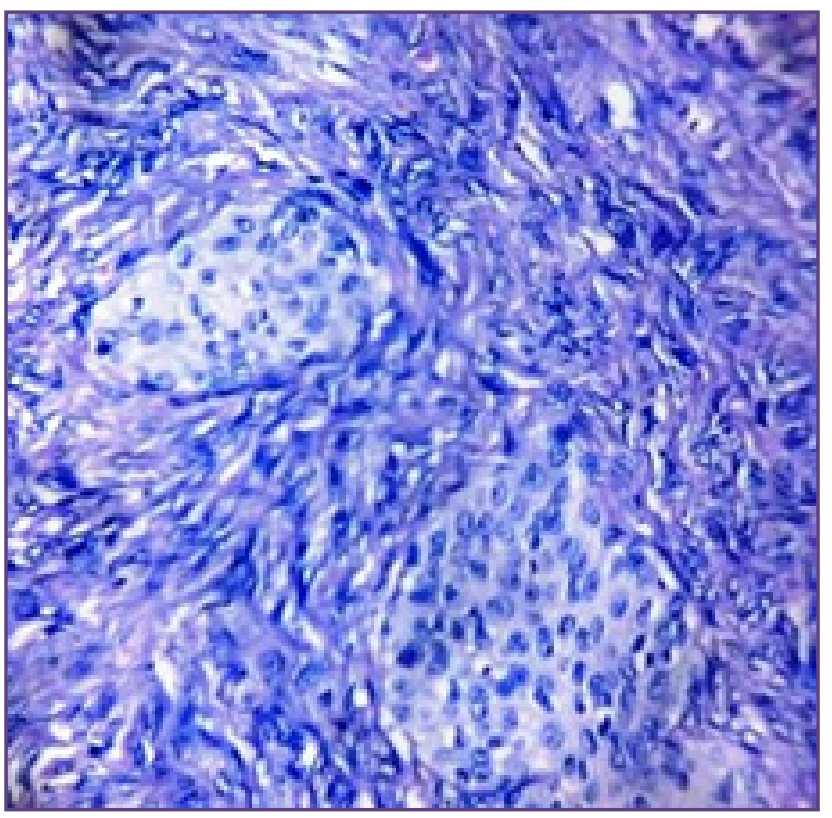

Fig. 6: H \& E Micro Brenner showing solid nests of urothelium-like cells surrounded by abundant dense fibrous stroma $40 \mathrm{X}$

\section{Discussion}

In this study, majority of the ovarian tumors were benign (53 cases $-86.8 \%$ ). This data is similar to the data reported from other studies ${ }^{[12,13]}$ In the studies by Yasmin et al, Khan et al and Kayastha, the majority of the benign ovarian neoplasm were serous cystadenomas followed by mature cystic teratomas ${ }^{[13,14,15]}$ But Jha et al had observed mature cystic teratomas as the most common benign ovarian 
neoplasm. ${ }^{[16]}$ However, in this study majority of the benign ovarian neoplasms were serous cystadenomas followed by mucinous cystadenoma.

The percentage of malignant ovarian neoplasms was $13 \%$ (8 cases) in this study, which is lower than what had been reported by Shaikh et al (31\%) and Gupta et al $(22.9 \%)^{\cdot[6,7]}$

There is a great difference in the frequency of different categories of malignant neoplasms in the various studies in comparison to the present study. Jha et al had observed serous cystadenocarcinoma (46.2\%) as the most common malignant ovarian neoplasm [16] Yasmin et al observed granulosa cell tumors and endometrioid carcinoma $(28.5 \%)$ each as the most common malignant ovarian neoplasm ${ }^{[14]}$ Similar to the study conducted by Jha et al, ${ }^{[16]}$ the most common malignant ovarian neoplasm in the present study was serous cystadenocarcinoma $(37.5 \%)$.

Only $1.6 \%$ of borderline tumor was observed in the present study, which was lower than the studies conducted by Gupta et al ${ }^{[7]}$ and Okugawa et al ${ }^{\left[{ }^{[8]}\right.}$ where both the studies had observed $4 \%$ of the borderline ovarian tumors.

When the overall histological variety is concerned, the present study observed that the most of the tumors originate from the surface epithelium $(86.88 \%)$. The frequency of surface epithelial tumors is approximately similar to the other studies conducted in Nepal ${ }^{[5]}$ and India ${ }^{[7,9]}$ However, the frequency of surface epithelial tumors was above $70 \%$ in the studies by Kayastha ${ }^{[13]}$ Sarwar ${ }^{[10]}$ and Yasmin. ${ }^{[14]}$

Next to the surface epithelial tumors, the second most common ovarian neoplasm was germ cell tumor, which constituted $8.1 \%$ in the present study. This result is comparable with the study carried out at Tribhuvan University Teaching Hospital, Nepal, ${ }^{[16]}$ in which germ cell tumors were the second common tumors (42.2\%); and is also comparable with different series of studies ${ }^{[14,15,6,7,8]}$

Bhattacharya et al, ${ }^{[9]}$ and Khan et al ${ }^{[[15]}$ noticed benign neoplasms occurring mostly in between 21 and 40 years of age. The present study observed benign neoplasms in the age group from 21 and above 60 years of age.

Of all malignant ovarian neoplasms, the most common were surface epithelial tumors, which were lower in the study done in Nepal by Maharajan et al, ${ }^{[11]}$ where the most common malignant neoplasms were germ cell tumors. Similar to the study by Vaidya et al,,$^{[12]}$ in which malignant surface epithelial tumor was observed above the age of 50 years, the present study had noticed a case of malignant surface epithelial tumor in a patient above the age of 50 years.

The present study had observed sex cord-stromal tumors in age group of 41 to 60 years which is similar to the study conducted by Maharjan et al. ${ }^{[11]}$

The present study constituted 5 cases $(8 \%)$ of germ cell tumors out of 61 cases out of which one was malignant, 1 case of malignant germ cell tumor above the age of $50 y e a r s$. Benign germ cell were between 21 to 40years of age. Similarly the study by Vaidya et al in Nepal also shows benign germ cell tumors common between the age group of 21 to 40 years of age . ${ }^{[12]}$

The current study shows 3 cases of sex cord-stromal tumors between 41 and 60 years of age. Likewise the study conducted by Maharjan et al, ${ }^{[11]}$ also shows sex cordstromal tumors between 41 and 60 years of age

This current study shows various clinical presentations of ovarian tumors. Many patients experienced more than one symptom which is similar to study conducted by Kayastha et al. ${ }^{[13]}$

The most common symptom was abdominal pain (32 cases - 52.4\%), followed by abdominal mass (6 cases- $9.8 \%$ ). This is comparable with the other studies conducted by Kayastha et al ${ }^{[13]}$ and Yasmin et al ${ }^{\left[{ }^{[3]}\right.}$ In this study, 3 cases $(5 \%)$ also had other constitutional symptoms like loss of appetite and loss of weight.

In the present study, 3 cases were bilateral out of which 2 were malignant (serous cystadenocarcinoma) and 1 was benign (serous cystadenofibroma). This result is comparable with the study conducted by Bhattacharya et al ${ }^{[9]}$ in India were they noticed bilaterality was seen more common among malignant tumors. But the study conducted by Maharjan et al, ${ }^{[1]}$ shows most bilaterality was observed in the benign tumors.

Serous carcinoma grossly they were cystic predominantly with papillary excrescences (Figure 2) also solid, hard masses seen. Out of 3 serous carcinoma 2 were bilateral (Table 2). Microscopically serous carcinoma had branching papillary fronds, glandular complexity, with marked nuclear pleomorphism and atypia. Cribriform, solid, glandular architecture and also predominate. Areas of necrosis and hemorrhage were seen in many of our cases. Also psammoma bodies and lymphovascular invasion seen(Table 2).

Mucinous carcinoma of ovary $77 \%$ are metastases and only $23 \%$ are ovarian primaries ${ }^{[17]}$ Of the ovarian primaries most arises in a benign or borderline tumour, only $5-10 \%$ 
are pure. mucinous carcinoma shows a limited range of histologic appearance. In our study we observed 1 case of mucinous borderline tumour and 7 cases of benign mucinous cystadenoma and 1 case of mucinous carcinoma out of 9 mucinous tumours. Borderline Mucinous tumour presented on the left side ovary measuring $4.5 \mathrm{~cm}$ in diameter multiloculated containing mucin (Figure 5) and Right side ovary mucinous cystadenoma was diagnosed. Microsopically broad papillae lined by intestinal type with epithelial atypia was seen. Stromal invasion was absent and the atypical epithelium was less than four cells in thickness.so a diagnosis of borderline mucinous tumour was made.

Mucinous cystadenocarcinoma, 35years female presented with left side abdominal maas. Total abdominal hysterectomy with bilateral salphingoophorectomy was done. Gross left side ovary was enlarged measuring $22 \mathrm{~cm}$ External surface was smooth. Cut surface was partially solid to cystic multiloculated containing mucinous material .Microscopically showed intracytoplasmic mucin.(Figure 3) with cellular atypia, stratification, papillae, Necrosis, with greater complexity of glands.

Mucinous tumors may show overt gland formation with reduced intracytoplasmic mucin mimicking an endometrioid carcinoma. So the main differential diagnosis will be endometrioid carcinoma, serous carcinoma with intraluminal mucin and metastatic adenocarcinoma ${ }^{[18]}$ Absence of endometriosis and squamous metaplasia with coexisting mucinous borderline tumor favor a mucinous neoplasm instead of an endometrioid tumor. ${ }^{[18]}$

Brenner tumours most commonly occurs in elderly women from $50-70$ years of age ${ }^{[19]}$ Only $5 \%$ of them are malignant. ${ }^{[19]}$ Malignant Brenner tumours typically have both solid and cystic components grossly. Cyst may show papillary masses or solid nodules on their wall ${ }^{[20]}$ In ourstudy we found 1 case of Micro Brenner tumour (Figure 6)which was an incidental finding where Hysterectomy with bilateral salphingooporectomy was done for Dysfunctional uterine bleeding with leiomyoma.

The commonest complication in the present study was ovarian tortion observed in 2 cases presented with acute abdomen. Kayastha, ${ }^{[21]}$ had also observed tortion as the commonest complication (12.6\%).

\section{Conclusion}

In this study, the most common ovarian tumor was surface epithelial tumors and the most common benign tumor among surface epithelial tumor was serous cystadenoma. The commonest malignant tumor was surface epithelial tumor which was common among patients who are above 60 years of age. The common presenting symptom was abdominal pain and the most common complication was ovarian tortion.

\section{References}

1. Kumar, V., \& Robbins, S. L. 1. (2007). Robbins basic pathology (9th ed.).Chapter 22; The Female Genital Tract; 1022

2. Parkin DM, Bray F, Ferlay J, Pisani P. Global cancer statistics, 2002. CA Cancer J Clin.2005;55(2):74-108

3. Consolidated Report of the Population Based Cancer Registries 2001-2004: National Cancer Registry Programme. Bangalore: Indian Council of Medical Research; 2006.

4. Jemal A, Siegel R, Ward E, Murray T, Xu J, Smigal C, et al. Cancer statistics, 2006. CA Cancer J Clin.2006;56(2): 106-30

5. Murthy NS, Shalini S, Suman G, Pruthvish S, Mathew A. Changing Trends in Incidence of Ovarian Cancer - the Indian Scenario. Asian Pacific Journal of Cancer Prevention, 2009; 10(6): 1025-1030..

6. Shaikh NA, Hashmi F, Samoo RP. Pattern of ovarian tumors: report of 15 years experience at Liaquat University Jamshoro. J LiaquatUni Med Health Sci 2007;6:13-5.

7. Gupta N, Bisht D, Agarwal AK, Sharma VK. Retrospective and prospective study of ovarian tumors and tumor-like lesions. Indian J PatholMicrobiol 2007;50(3):525-7

8. Okugawa K, Hirakawa T, Fukushima K, Kamura T, Amada $\mathrm{S}$, Nakano H. Relation between age, histological type and size of ovarian tumors. Int J GynecolObstet 2001;74(1):4550.

9. Bhattacharya MM, Shinde SD, Purandare VN. A clinicopathological analysis of 270 ovarian tumors. J Postgrad Med 1980;26(2):103-7.

10. Sarwar CM, Siddiqui N, Khokhar RA, Badar F. Epithelial ovarian cancer at a cancer hospital in a developing country. Asian Pac J Cancer Prev 2006;7(4):595-8.

11. Maharjan S. clinicomorphological study of ovarian lesions; journal of chitwan medical college 2013;3(6):17-24

12. Vaidya S, Sharma P, KC S, Vaidya SA. Spectrum of ovarian tumors in a referral hospital in Nepal. Journal of Pathology of Nepal 2014; 4: 539 -543.

13. Kayastha S. Study of ovarian tumors in Nepal Medical College Teaching Hospital. Nepal Med Coll J 2009;1 (3):200-2.

14. Yasmin S, Yasmin A, Asif M. Clinicohistological pattern of ovarian tumours in Peshawar region. J Ayub Med Coll Abbottabad 2008; 20: 11-13.

15. Khan AA, Luqman M, Jamal S, Mamoon N, Mushtaq S. Clinicopathologicalanalysis of ovarian tumors. Pak J Pathol 2005;16(1):28-32

16. Jha R, Karki S. Histological pattern of ovarian tumors and their age distribution. Nepal Med Coll J 2008;10(2):81-5. 
17. Seidman JD, Kurman RJ, Ronnett BM. Primary and metastatic mucinous adenocarcinomas in the ovaries: incidence in routine practice with a new approach to improve intraoperative diagnosis. Am J SurgPathol.In press 2003.

18. Soslow RA. Histologic Subtypes of Ovarian Carcinoma: An Overview. International Journal of Gynecological Pathology2008;27:161-74
19. Hallgrimsson J, Scully RE. borderline and malignant Brenner tumours of the ovary. A report of 15 cases. ActaPathol Microbial Scand. 1972;233:56-6.

20. Scully RE, Young RH, Clement PB. Tumors of the ovary, maldeveloped gonads, fallopian tube, and broad ligament, 3rd series, no.23. Washington, DC: Armed Forces Institute of Pathology,1998. pp153-4.

*Corresponding author:

Dr.Vimala Chelladurai, No 18/13,Second Cross Street,Gopal Reddy Colony,Perambur,Chennai(India) 600082

Phone: +91 9940334018

Email: Vimalachelladurai89@gmail.com

Date of Submission : 08.09.2017

Date of Acceptance : 10.10.2017

Financial or other Competing Interests: None.

Date of Publication : 28.01.2018 